\title{
PENGARUH LOCUS OF CONTROL (LOC) TERHADAP QUALITY OF LIFE (QOL) PADA PASIEN DIABETES MELITUS (DM) TIPE II DI RSUD KOTA MAKASSAR TAHUN 2018
}

\author{
Hadisa Kuniyo ${ }^{1}$, Yusran Haskas ${ }^{2}$, Syaifuddin Zainal ${ }^{3}$ \\ ${ }^{1}$ STIKES Nani Hasanuddin Makassar \\ ${ }^{2}$ STIKES Nani Hasanuddin Makassar \\ ${ }^{3}$ STIKES Nani Hasanuddin Makassar
}

Alamat korespondensi : (Ichakuniyo@gmail.com)/082198149887

\begin{abstract}
ABSTRAK
Diabetes melitus (DM) adalah kumpulan gejala yang timbul pada seseorang yang disebabkan oleh karena adanya peningkatan kadar glukosa darah akibat penurunan sekresi insulin yang progresif yang dilatar belakangi oleh resistensi insulin. Tujuan penelitian ini untuk mengetahui Pengaruh locus of control (LOC) terhadap quality of life (QOL) pada pasien Diabetes Melitus tipe II di RSUD Kota Makassar. Penelitian ini merupakan jenis penelitian survey analitik dengan metode cross sectional. Pengambilan sampel menggunakan teknik consecutive sampling, didapatkan 37 responden sesuai dengan kriteria inklusi. Pengumpulan data dilakukan dengan menggunakan kuesioner. Data yang telah dikumpul kemudian diolah dan dianalisis dengan menggunakan komputer program microsoft excel dan program statistik (SPSS) versi 22.0. Analisis data mencakup analisis univariat dengan mencari distribusi frekuensi, analisis bivariat dengan uji chi-squere $(a=0.05)$ untuk mengetahui hubungan antar variabel. Hasil analisis bivariat didapatkan Pengaruh locus of control terhadap quality of life pada pasien Diabetes Melitus tipe II $(\rho=0.038)$. Kesimpulan dalam penelitian ini adalah ada Pengaruh locus of control (LOC) terhadap quality of life (QOL) pada pasien Diabetes Melitus tipe II di RSUD Kota Makassar. Disarankan pada penderita Diabetes Melitus (DM) tipe II dianjurkan untuk melakukan pencegahan dengan melakukan aktivitas secara rutin dan memperbanyak aktivitas di rumah. Selain itu melakukan kontrol gula darah secara rutin.
\end{abstract}

Kata kunci: Diabetes melitus, locus of control, quality of life

\section{PENDAHULUAN}

Saat ini perhatian penyakit tidak menular semakin meningkat karena frekuensi kejadiannya pada masyarakat semakin meningkat. Dari sepuluh penyebab utama kematian, dua diantaranya adalah penyakit tidak menular. Salah satunya Diabetes Melitus merupakan penyakit yang tidak menular yang mengala mi peningkatan terus-menerus dari tahun ke tahun. Diabetes melitus (DM) merupakan sebuah penyakit, di mana kondisi kadar glukosa di dalam darah melebihi batas normal (Putri \& Isfandiari, 2013:234- 235).

Menurut World Health Organization (WHO) jumlah penderita diabetes menjadi 422 juta pada tahun 2014, itu menandakan terjadinya peningkatan secara signifikan dari jumlah awal sekitar 108 juta di tahun 1980an. Diabetes melitus pada orang dewasa di atas 18 tahun sebanyak $8,5 \%$ pada tahun 2014 , itu menandakan terjadinya peningkatan dari $4,7 \%$ pada tahun 1980an.

Menurut laporan Centers For Disiase and Prevention (CDC), di American Diabetes Association (ADA) pada tahun 2015 sebanyak $9,4 \%$ dari populasi menderita diabetes melitus melitus terdiri dari 30,3 juta orang Amerika.
Sekitar 1,25 juta anak Amerika dan orang dewasa memiliki diabetes tipe I. Dari 30,3 juta orang dewasa dengan diabetes, 23,1 juta didiagnosis dan 7,2 juta tidak terdiagnosis.

Data menurut Riset Kesehatan Dasar (Riskesdas) tahun 2018 prevalensi diabetes melitus di Indonesia berdasarkan wawancara yang terdiagnosis dokter pada penduduk umur lebih dari 15 tahun sebesar 2,0\% pada tahun 2018. Berdasarkan data tersebut bahwa terjadi peningkatan sebesar $0,5 \%$ dari prevelesi pada tahun 2013 yang hanya sebesar $1,5 \%$. Prevalensi diabetes melitus yang terdiagnosis dokter tertinggi terdapat di DKI Jakarta $(3,4 \%)$, Kalimantan Timur $(3,2 \%)$ Yogyakarta $(3,1 \%)$, Sulawesi Utara $(3,0 \%)$, Jambi $(2,8 \%)$ dan terendah daerah NTT $(0,9 \%)$.

Selain itu, Diabetes melitus Tipe II merupakan penyakit yang berada dalam urutan 5 besar penyakit terbanyak di instalasi rawat jalan di RSUD Daya. Setiap tahun penyakit ini mengalami peningkatan. Pada tahun 2016 terdapat 1.405 penderita dan meningkat menjadi 2.019 pada tahun 2017 dan kembali terjadi penigkatan pada Tahun 2018 (dari bulan Januari sampai September) 
sebanyak 338 dengan kasus baruh. (Rekam Medik RSUD Kota Makassar, 2018).

Gaya hidup moderen perkotaan sangat mempengaruhi peningkatan prevalensi Diabetes Melitus. Penyakit diabetes melitus ini mempegaruhi life style terhadap penderita diabetes melitus tipe II sehingga berdampak buruk terhadap quality of life. Penurunan quality of life pada pasien Diabetes Melitus ditandai dengan ketidaksanggupan pasien tersebut melakukan pengontrolan diri secara mandiri yang disebut locus of control (loc).

Berdasarkan fonemena yang terjadi prevalensi DM tipe II di didapatkan hasil yang setiap tahunnya cenderung meningkat di RSUD Kota Makassar diakibatkan banyaknya kebiasaan masyarakatnya yang suka mengkonsumsi makananan yang tinggi karbohidrat tanpa mengontrol gula darahnya dan juga jarang melakukan aktivitas fisik seperti berolahraga. Berdasarkan latar belakang permasalahan di atas maka peneliti tertarik untuk mengetahui "Pengaruh Locus Of Control (LOC) terhadap Quality Of Life (QOL) pada pasien Diabetes Melitus tipe II di RSUD Kota Makassar".

\section{BAHAN DAN METODE}

Lokasi, Populasi dan Sampel

Penelitian ini dilaksanakan di Rumah

Sakit Daya Kota Makassar, tanggal 12 Desember 2018 sampai dengan tanggal 07 Januari 2019 di ruangan Perawatan internal. Populasi dalam penelitan ini adalah semua pasien yang menderita diabetes melitus sebanyak 338 orang. Jumlah sampel pada penelitian ini 37 orang. Pengambilan sampel dilakukan dengan tehnik consecutive sampling.

a. Kriteria Inklusi

1. Pasien diabetes melitus tipe II di ruangan perawatan internal dalam RSUD Kota Makassar.

2. Pasien yang bias membaca dan menulis

3. Pasien yang bersedia menjadi responden.

b. Kriteria Eksklusi

1. Pasien diabetes melitus dengan sakit atau kondisi tidak memungkinkan (penurunan kesadaran).

2. Pasien yang tidak dapat berkomunikasi.

\section{Pengumpulan Data}

1. Data Primer

Data primer yang digunakan dalam penelitian ini diperoleh dari kuesioner yang terdiri dari pertanyaan pembahasan seputar diabetes melitus.
2. Data Sekunder

Data sekunder dalam penelitian ini diperoleh dan dikumpulkan peneliti tentang jumlah penderita diabetes melitus di RSUD Kota Makassar.

\section{Langkah Pengelolahan Data}

1. Editing

Hasil wawancara angket, atau pengamatan dari lapangan harus dilakukan penyuntingan (editing) terlebih dahulu. Secara umum editing adalah merupakan kegiatan untuk pengecekan dan perbaikan isian formulir atau kuesioner.

2. Coding

Kuesioner semua setelah diedit atau disunting, selanjutnya dilakukan peng "kodean" atau "coding", yakni mengubah data berbentuk kalimat atau huruf menjadi data atau angka bilangan.

3. Data Entry (memasukkan data) atau Processing

Data, yakni jawaban dari setiap responden yang dalam bentuk "kode" (angka atau huruf) dimasukkan ke dalam program atau "software" computer.

\section{Analisa Data}

1. Analisis Univariat

Tekhnik ini dilakukan terhadap setiap variabel hasil dari penelitian. Hasil dari analisis ini berupa distribusi frekuensi, tendensi sentral, ukuran penyebaran maupun presentase dari setiap variabel Analisis Bivariat

2. Analisis Bivariat

Merupakan model analisis untuk mengetahui interaksi dua variabel, baik berupa komparatif, asosiatif, maupun korelatif dengan menggunakan uji ChiSquare.

\section{HASIL PENELITIAN}

1. Analisa Univariat

Tabel. 1 Distribusi Karakteristik Responden pasien DM di RSUD Kota Makassar $(n=37)$

\begin{tabular}{|c|c|c|}
\hline Karakteristik & $\mathrm{n}$ & $\%$ \\
\hline Jenis Kelamin & & \\
Laki-laki & 12 & 32,4 \\
Perempuan & 25 & 67,6 \\
\hline Umur & & \\
36-45 Tahun & 8 & 21,6 \\
46-55 Tahun & 17 & 45,9 \\
56-65 Tahun & 12 & 32,4 \\
\hline Pendidikan Terakhir & & \\
Tidak Sekolah & 2 & 5,4 \\
SD & 1 & 2,7 \\
SMP & 12 & 32,4 \\
SMA & 18 & 48,6 \\
Perguruan tinggi & 4 & 10,8 \\
\hline
\end{tabular}




\begin{tabular}{|c|c|c|}
\hline Pekerjaan & & \\
Tidak Bekerja & 5 & 13,5 \\
IRT & 11 & 29,7 \\
Pegawai Swasta & 5 & 13,5 \\
Wiraswasta & 16 & 43,2 \\
\hline
\end{tabular}

Berdasarkan tabel di atas menunjukkan umumnya responden lebih banyak berjenis kelamin perempuan yaitu 25 responden $(67,6 \%)$ dan laki-laki 12 responden $(32,4 \%)$, responden yang berumur 46-55 tahun yaitu 17 responden $(45,9 \%)$ dan paling sedikit adalah responden yang berumur 36-45 tahun sebanyak 8 responden $(21,6 \%)$, responden paling banyak adalah SMA 18 responden $(48,6 \%)$ dan paling sedikit adalah SD/sederajat 1 responden $(2,7 \%)$ dan responden yang bekerja sebagai Wiraswasta lebih dominan 16 responden $(43,2 \%)$, sedangkan paling sedikit adalah responden yang bekerja sebagai pegawai swasta dan tidak bekerja 5 responden $(13,5 \%)$.

2. Analisis Bivariat

Tabel. 2 Pengaruh LOC terhadap QOL pada pasien DM Tipe II di RSUD Kota Makassar. $(n=37)$

\begin{tabular}{|c|c|c|c|c|c|c|}
\hline \multirow{2}{*}{ LOC } & \multicolumn{4}{|c|}{ QOL } & \multicolumn{2}{c|}{ Total } \\
\cline { 2 - 5 } & \multicolumn{2}{|c|}{ Baik } & \multicolumn{2}{c|}{ Kurang } & \multicolumn{2}{c|}{} \\
\cline { 2 - 7 } & $\mathrm{n}$ & $\%$ & $\mathrm{n}$ & $\%$ & $\mathrm{n}$ & $\%$ \\
\hline $\begin{array}{c}\text { Inter } \\
\text { Nal }\end{array}$ & 13 & 81,3 & 3 & 18,8 & 16 & 100 \\
\hline $\begin{array}{c}\text { Mod } \\
\text { erat }\end{array}$ & 4 & 10,8 & 0 & 0,0 & 4 & 100 \\
$\begin{array}{c}\text { Exter } \\
\text { nal }\end{array}$ & 8 & 47,1 & 9 & 52,9 & 17 & 100 \\
\hline Total & 25 & 67,6 & 12 & 32,4 & 37 & 100 \\
\hline \multicolumn{7}{|c|}{$\rho=0,038$} \\
\hline
\end{tabular}

Berdasarkan hasil analisis tabel diatas bahwa dari keselurah sebanyak 37 responden menunjukkan bahwa 17 reponden $(45,9 \%)$ cenderung external locus of control dimana terdapat responden yang memiliki quality of life yang baik sebanyak 8 responden $(47,1 \%)$ dan yang kurang sebanyak 9 responden $(52,9 \%)$, sebanyak 16 responden $(43,2 \%)$ cenderung internal locus of control dimana terdapat responden yang memiliki quality of life yang baik sebanyak 13 responden $(81.3 \%)$ dan yang kurang sebanyak 3 responden $(18,8 \%)$ kemudian sebanyak 4 responden $(10,8 \%)$ cenderung moderat dimana terdapat responden yang memiliki quality of life yang baik sebanyak 4 responden $(10,8 \%)$ dan yang kurang sebanyak 0 responden (0,0\%). Berdasarkan uji pearson Chi-Square diperoleh nilai $\rho=0,038$, dengan demikian Ha diterima dan Ho ditolak sehingga dapat disimpulkan ada pengaruh locus of control terhadap quality of life pada pasien diabetes melitus tipe II di RSUD Kota Makassar.

\section{PEMBAHASAN}

Berdasarkan tabel penelitian diatas menggambarkan bahwa pada hasil penelitian menunjukkan ada pengaruh yang signifikan antara locus of control terhadap quality of life pada pasien diabetes melitus tipe II dengan hasil penelitian $\rho=0,038<\alpha=0,05$. Keseluruhan sebanyak 37 responden menunjukkan sebanyak 25 responden $(67,6 \%)$ memiliki quality of life yang baik sedangkan 12 responden $(32,4 \%)$ memiliki quality of life yang kurang. Terjadinya peningkatan quality of life pada pasien diabetes melitus tipe II di pengaruhi oleh locus of control baik internal maupun external. Menurut WHO,. 2012 mendefenisikan kualitas hidup sebagai persepsi individu dalam kehidupan dan konteks budaya serta sistem nilai yang terkait dengan tujuan, harapan, standar, dan perhatian.

Penelitian lain terkait dengan quality of life yang di lakukan (Rantung dkk,. 2015) mengatakan bahwa ada hubungan yang signifikan antara self care dengan kualitas hidup pasien diabetes melitus.

Penelitian lain yang di lakukan (Tamara dkk,. 2014) mengenai hubungan keluarga dengan kualitas hidup pasien diabetes melitus mengatakan bahwa ada hubungan antara dukungan keluarga dengan kualitas hidup pasien diabetes melitus.

Locus of control sangat erat kaitannya terhadap quality of life, dimana ketika individu dengan Locus of controlnya baik maka akan menghasilkan kualitas hidupnya yang baik. Kualitas hidup penderita diabetes melitus dipengaruhi oleh beberapa faktor diantaranya kepatuhan diet, kepatuhan minum obat dan dukungan keluarga. Locus of control individu juga dipengaruhi oleh kesadaran akan kesehatan yang dialaminya, ketika individu memiliki niat untuk melakukan perubahan terhadap dirinya maka akan terjadi perubahan dalam kualitas hidupnya.

Hasil penelitian pada pengaruh locus of control terhadap quality of life pada pasien diabetes melitus tipe II di RSUD Kota Makassar didapatkan bahwa responden cenderung memiliki internal locus of control dibandingkan dengan external locus of control. Hal ini karena individu percaya bahwa hasil 
yang baik yang diperoleh dari kegagalan merupakan hasil dari perilakunya sendiri, sehingga ia percaya bahwa yang menggontrol berhasil tidaknya suatu tujuan adalah dirinya sendiri.

Merujuk dari penelitian sebelumnya yang dilakukan (Safitri,. 2013) mengatakan bahwa kebudayaan merupakan salah satu faktor yang mempengaruhi locus of control seperti budaya barat dan budaya timur. Secara umum, budaya barat lebih cenderung memiliki locus of control internal dan budaya timur lebih cenderung memiliki locus of control external. Orang dengan status sosio-ekonomi rendah cenderung mengembangkan health locus of control external. Hasil penelitian ini sejalan dengan pernyataan tersebut bahwa dari keseluruhan responden menunjukkan respon yang yang tidak bekerja dan IRT lebih banyak dan memiliki locus of control external.

Penelitian lain yang dilakukan oleh (Haskas,. 2016) mengatakan bahwa pengalaman penderita diabetes mempengaruhi perilaku kontrol diabetes. Hasil distribusi frekuensi pengalaman penderita diabetes, baik penderita diabetes yang memiliki pengalaman menyenangkan atau tidak menyenangkan menunjukkan rata-rata $62,2 \%$ dalam mengendalikan diabetes.

Penelitian serupa yang dilakukan oleh (Haskas., 2017) tentang Pengaruh niat penderita terhadap perilaku pengendalian diabetes melitus di kota makassar mengatakan bahwa ada pengaruh niat penderita terhadap perilaku pengendalian diabetes melitus. Penelitian lain yang dilakukan oleh (Haskas dkk,. 2016) mengemukakan bahwa pusat kontrol (locus of control) secara signifikan mempengaruhi niat pasien DM untuk melakukan kontrol DM. Penelitian yang dilakukan oleh (Nuraini, dkk,. 2013) mengatakan bahwa lebih banyak respon den yang memiliki locus of control external dibandingankan dengan locus of control internal.

Internal Locus of control memiliki kendali yang lebih besar terhadap keyakinan dalam diri dan menganggap semua yang terjadi pada dirinya tergantung dari perilaku yang dilakukanya. Responden yang memiliki Locus of control internal cenderung memiliki pengaruh lebih besar terhadap peningkatan quality of life khusunya pada pasien diabetes melitus tipe II. Selain external locus of control dan internal locus of control juga terdapat moderat locus of control, hal ini disebabkan oleh sama besarnya pengaruh terhadap perubahan perilaku responden baik pengaruh internal maupun external locus of control, walaupun demikian responden yang memiliki moderat locus of control cenderung memiliki quality of life yang kurang, dikarenakan oleh terjadinya perilaku yang tidak konsisten yang diterapkan oleh individu itu sendiri.

Hasil penelitian ini sejalan dengan yang dilakukan oleh (Budiansyah, 2014) mengemukakan bahwa hasil analisis didapatkan gambaran locus of control pada penderita lansia tionghoa penyakit hipertensi dengan aspek internal locus of control lebih tinggi dibandingkan external locus of control. Penelitian lain yang sejalan adalah penelitian yang dilakukan (Manto, dkk., 2017) mengatakan bahwa dalam dimensi god locus of health Control menunjukkan tidak adanya korelasi dengan kepatuhan pengobatan. karena pada dasarnyan individu yang memiliki locus of control internal memiliki tingkat kepatuhan lebih tinggi dibandingkan dengan individu yang memiliki locus of control eksternal (god locus of health control). Berdasarkan penelitian tersebut peneliti berasumsi bahwa internal locus of control lebih dominan di bandingkan dengan external locus of control.

Hasil penelitian ini sesuai dengan penelitian yang dilakukan (Safitri, 2013) mengatakan bahwa ada perbedaan kepatuhan yang signifikan ditinjau dari locus of control. Subjek yang memiliki locus of control internal memiliki nilai kepatuhan yang tinggi dibandingkan dengan locus of control exsternal powerful others dan chance.

Berdasarkan urain di atas, peneliti juga dapat menyimpulkan bahwa locus of control (internal dan external) memiliki pengaruh terhadap quality of life. Hal ini menunjukkan bahwa responden memiliki tingkat pengendalian dalam diri dan menyadari bahwa dirinya memiliki peran yang besar untuk meningkatkan derajat kesehatannya namun belum mampu mengaplikasikannya dengan baik dalam mengatur pola hidup yang benar, selain itu besarnya pengaruh dari luar juga mempengaruhi responden yang diakibatkan oleh ketidakmampuan mengambil keputusan secara individu, walaupun demikian locus of control (internal dan external) keduanya mampu meningkatkan tingkat quality of life pada pasien diabetes melitus tipe II.Walaupun demikian setelah locus of control dilakukan korelasi terhadap quality of life peneliti dapat meyimpulkan bahwa interna locus of control lebih dominan dibandingkan dengan external locus of control. Hal ini menujukkan bahwa responden yang memiliki internal locus of control memberikan energi yang positif terhadap perilaku individu terutama pada kepuasan perawatan, tentang kondisi keuangan dan emosional sehingga mampu 
mempengaruhi peningkatan quality of life menjadi lebih baik.

\section{KESIMPULAN}

1. Ada pengaruh locus of control terhadap quality of life pada pasien diabetes melitus tipe II di RSUD Kota makassar.

2. Internal locus of control lebih dominan terhadap quality of life pada pasien diabetes melitus tipe II di RSUD Kota makassar.

\section{SARAN}

1. Penderita diabetes melitus tipe II agar lebih memperhatikan kondisi kesehatannya dengan melakukan kontrol terhadap perilaku baik dengan internal locus of control maupun external locus of control sehingga dapat mengendalikan gula darah dalam batas normal.

2. Keluarga pasien harus memotivasi pasien agar selalu memertahankan dan meningkatkan quality of life pada pasien diabetes melitus tipe II, karena dukungan dari orang terdekat sangat diperlukan untuk dapat mengontrol kadar gula darah pasien agar tetap stabil sehingga dapat meningkatkan $Q O L$.

3. Peneliti selanjutnya diharapkan dapat melakukan penelitian lebih mendalam terhadap hubungan LOC dengan terkendalinya kadar gula darah dan QOL pada pasien diabetes melitus tipe I dan II.

\section{DAFTAR PUSTAKA}

ADA. (2015). Diabetes Basics Statistics. (http://www.diabetes.org/diabetes-basics/ statistics/?loc=db-slabnav). Diakses pada 25 Oktober 2018.

Budiansyah, F, D (2015). Hubungan Health Belief dengan Health Locus of Control Pada Lansia Etnis Tionghoa Yang Memiliki Penyakit Di Kelompok Senam Aerobik. Skripsi. Fakultas Psikologis. Univesion Islam Bandung: Bandung. Sumber dari: http//repository.unisba.ac.id/handle/123456789/312 (Diakses pada tanggal 30 januari 2019)

Tamara, E., Bayhakki,, Fathra, A.N. 2014. Hubungan antara Dukungan Keluarga dan Kualitas Hidup Pasien Diabetes Mellitus Tipe II di RSUD Arifin Achmad Provinsi Riau. JOM PSIK. Vol. 1 No.2. 22 Juni 2017. Tersedia di TNR.

Haskas, Y. (2016). The Influence of Diabetic Experience against the Behavior of DM Controlling. International Journal of Sciences: Basic and Applied Research (IJSBAR) 4531, 41-47. http://gssrr.org/index.php?journal=JournalOfBasicAndApplied\&page=article\&op=view\&path\%5B\%5D=586 $\underline{9}$ (Diakses pada tanggal 3 januari 2019)

Haskas, Y. (2017). Pengaruh Niat Penderita Terhadap Perilaku Pengendalian Diabetes Melitus Di Kota Makassar. Global Health Science Journal 2(4), 409-412. http://jurnal.csdforum.com/index.php/GHS/article/view/85 (Diakses pada tanggal 3 januari 2019)

Haskas, Y., Suryanro. \& Widodo, J. P. (2016). The Effect of ' Locus of Control ' on the Diabetes Mellitus Patients 'Intention in Performing the DM Control. International Journal of Sciences: Basic and Applied Research (IJSBAR) 4531, 130-136. http://gssrr.org/index.php?journal=JournalOfBasicAndApplied\&page=article\&op=view\&path\%5B\%5D=527 1 (Diakses pada tanggal 3 januari 2019)

Machfoedz, I. (2016). Metodologi Penelitian (Kuantitatif \& Kualitatif). Yogyakarta: Fitramaya:93

Masyithoh, N. D. (2014). Hubungan Antara Locus Of Control Dengan Kepatuhan Minum Obat Pada Penderita Kusta. Skripsi. Malang:UMM. http://eprints.umm.ac.id/25945/1/jiptummpp-gdl-nurdewimas-37478-1pendahul-n.pdf (Diakses pada tanggal 30 Januari 2019)

Nuraini, A (2013). Hubungan antara selfeficacy dengan health locus of control pada penderita diabetes melitus tipe 2 anggota perkumpulan senam diabetes di puskesmas pakis Surabaya. Journal Universitas Airlangga, Surabaya. Vol. 1, No.1:22-27 htt/Jounal.Unair.ac.id/JPKK/article/877 (Diakses pada tanggal 04 februari 2019)

Putri, N., Isfandiari, M., 2013. Hubungan Empat Pilar Pengendalian DM Tipe 2 dengan Rerata Kadar Gula Darah. J. Berk. Epidemiol. 1, 234-243. http//repository.unair.ac.id/23150 (Diakses tanggal 18 januari 2016).

Rantung Jeanny, Yetti Krisna, H. T. (2015). Hubungan self-care dengan kualitas hidup pasien diabetes melitus $(\mathrm{dm})$ di persatuan diabetes indonesia (persadia) cabang cimahi, Jurnal Skolastik Keperawatan Vol 1, halaman 38-51. http://jurnal.unai.edu/index.php/jsk/article/view/17 (Diakses pada tanggal 20 Desember 2018) 
Riskesdas, (2018). Hasil Riset Kesehatan Dasar. (http://www.depkes.go.id/resources /download/general/Hasil\%20Riskesdas\%202013.pdf), 88. Diakses pada 31 Oktober 2018.

WHO.(2017).MediacentreFactsheets. (http://www.who.int/mediacentre/factsheets/ fs312/en/), 1-2. Diakses pada 27 Oktober 2018. 